coral, and the position of the bank in lat. $36^{\circ} 29^{\prime} \mathrm{N}$., long. $11^{\circ} 33^{\prime} \mathrm{W}$. In other words, Commander Gorringe, on his journey westward from the Strait, af́ter passing over the northern extremity of the deep channel, sounded up the steep slope of the submarine plateau which connects Portugal with Madeira, and within a short distance of a sounding of I, 525 fathoms obtained by H.M.S. Challenger on January 30,1873 , in lat. $36^{\circ} 23^{\prime} \mathrm{N}$., long. $11^{\circ} 18^{\prime} \mathrm{W}$.

The sketch-map does not pretend to be more than an approximation founded upon the still limited number of soundings obtained up to this date, but the bottom-temperatures observed in this part of the North Atlantic tend to corroborate the views which I have ventured to express. They show that the submarine flow of cold water of antarctic origin, which has been traced as far north as tire Bay of Biscay, also fills up the lower depths of the channel which stretches up towards Cape St. Vincent. On the other hand, the channel between the coast of Portugal and the Gettysburg Bank is occupied by the warm water of the Gulf Stream return-current, which, spreading itself out over the banks to westward, explains the presence of the live coral found by Commander Gorringe.

JOHN JAMES WILD

\section{HUMMOCKY MORAINE DRIFT}

T) URING his survey of the West Pacific slopes, Clarence King found and has since described, hummocks of moraine drift on the "dying-out glaciers," which are somewhat similar to the "hog-wallows;" and J. le Conte has described dying out glaciers and moraine drifts of California. Abstracts of these descriptions will be found in the American Fournal of Science and Arts, and the full description of the West Pacific

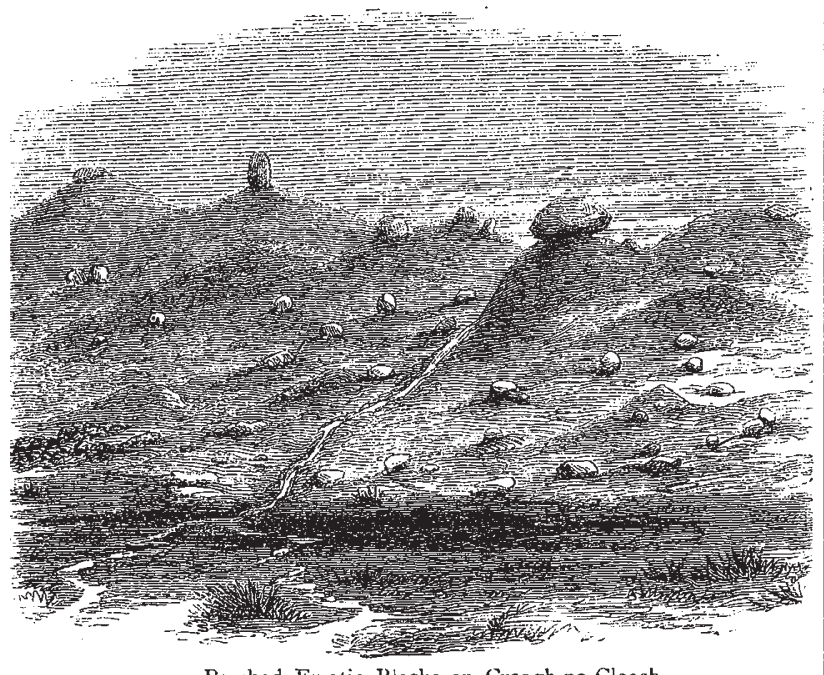

Perched Erratic. Blocks on Croagh-na-Cloosh.

slopes in Clarence King's report. In West Galway, Ireland, there are in places large tracts of drift sometimes like Clarence King's description, in others like the "hogwallow;" that in the Memoirs of the Irish branch of the Geological Survey have been described as "rocky moraine drift." The accompanying sketch is of some of these drift hummocks on the north slope of Croagh-naCloosh, south of Oughterard.

G. H. KINAHAN

\section{CONTRACTION OF THE LEAF OF "DIONAEA MUSCIPULA"}

I $N$ the first section of this paper the authors give an account of the mechanical effects which ensue on exciting the sensitive hairs of the Dionæa leaf. The following is a résumé of the principal conclusions at which the authors have arrived :-

I Abstract of paper on the Mechanical Effects and on the Electrical Disthe leaf af Dioncea muscipula, by J.
If the sensitive hair of a vigorous leaf be touched with very great care by a camel-hair pencil, no visible effect on the lea will be produced, and a similar gentle contact can be repeated several times before the leaf bejins to answer to the excitation by any movement. Sooner or later, however, the marginal hairs hend inwards and the lobe: slightly approach each other. The first effectual exciration is followed by an almost imperceptible movement; after this each successive approach of the lobes in nearly every case exceeds that of its predecessor. The interval which elapses between excitation and effect diminishes as the extent of the effect increases, both facts having the same meaning, namely that in the plant, as in certain cases well known to the animal physiologist, inadequate excitations, when repeated, exercise their infuence by what has been termed "summation," and thus the last contraction, that by which the leaf closes, is the result of the summation of the excitation which immediately preceded it with all the previous excitations. After the leaf has closed it still contracts at each excitation, and attempts to clench itself with greater and greater force. The interval between an excitation and the resulting movement varies from two to ten seconds.

The authors next proceed to a consideration of the electrical condition of the leaf in an unexcited-state, which has recently been made the subject of a minute investication ${ }^{1}$ by Prof. Munk, of Berlin, who has found-I. That if we conceive the external surface of the leaf divided into strips by parallel lines crossing the midrib nearly at right angles, and coinciding with the veining, any point of the external surface of each strip is negative to any point nearer the midrib. 2. That in comparing different points of the mid ib with each other, there is one whose position is two-thirds of the distance from the near to the far end of the midrib, which is positive to the rest. 3. He has further stated that the potential of any point on the internal surface of the lobe is exactly equal to that of the corresponding and opposite point on the external surface. Of these three proportions the first two are confirmed, in the main, by the authors of the present paper; as regards normal leaves, however, they take exception to $\mathrm{h} s$ conclusions on the two under-mentioned points- $(a)$ That although there is a spot of greatest positivity on the midrib, more or less corresponding in position to that mentioned by Prof, Munk, yet its position is by no means so definite as Prof. Munk states, but varies in different leaves. (b) That the different points in his isoelectrical negative line are never found to be absolutely identical. From the third propositicn the authors generally express their dissent. They, however, content themselves for the present with stating two general conclusions-I. That the part of the midrib which lies nearest the two central sensitive hairs is positive to every other part of the external surface of the leaf, but has usually the same polential as the petiole and other inactive parts of the plant. 2 . That the external surface, so long as the leaf is in vigour, is always positive to the internal surface.

The method used in this research differs from that generally empluyed in previous investioations, relating to animal or plant electricity, in two important particulars:-r. In the adoption of Lippmann's electrometer " (which has already been used by Prof. Marey in investigations on animal electricity) as the instrument for observing the electrical changes. 2 . In the substitution of a constant for a variable potential as a standard of comparison with the potential under investioation.

In comparing the potentials of two points the following arrangement was usually adopted:- The pot containing the plant ${ }^{3}$ had been previously kept plunged in water. Three non-polarisable electrodes were used, by one of them (the "fixed electrode") the damp surface of the pot is connected with the gas.pipes of the building, the other two ("movable electrodes") are in contact with the two points under observation. By means of a switch, either of these two movable electrodes can be brought into connection with one end of the electrometer, the other end being connected with earth.

When the whole of the outer surface of a leaf is covered with a mass of kaolin, moistened with salt-solution, and brought into connection with one end of the electrometer, the other end being connected by means of the fixed electrode with the petiole or pot, the effect of exciting a sensitive hair is to produce an

Burdon-Sanderson, M.D., F.R.S., Professor of Physiology in University College, and F. J. M. Page, B.Sc, F.C.S. Read before the Royal Society, December I4, 1876 .

Reicheri's and du Bois-Reymond's Archiv, 186

2 See the original paper, or Lippman, Pogg. Ann., 2873, 149, 546

3 Most of the observations were made ac kew in the month of August, I 876 , the plants being obtained from the Royal Gardens, through the kindness of the Director. 